\title{
Motivations of Information System Students in Final Project and their Implications to Technology and Innovation
}

\author{
Lavy I. \\ Management Information Systems Department, the Max Stern Yezreel Valley College, ISRAEL \\ E-mail: ilanal@yvc.ac.il \\ Rashkovits R. \\ Management Information Systems Department, the Max Stern Yezreel Valley College, ISRAEL \\ E-mail: ramir@yvc.ac.il
}

\begin{abstract}
In this study, we describe Information Systems students' decision making along their engagement with their final project regarding the complexity and innovations of their projects, and the technology they selected for the implementation. Data was gathered from projects' documentation; a questionnaire handed to the study participants, and from in-depth interviews conducted with representative group of them. Analysis of the data revealed that high achievers tend to develop innovative and complex final projects using major extensions of technologies learned in class while low achievers tend to develop simple and basic final projects using merely technologies learned in class or a minor extension of them. Surprisingly, some of the average and low achievers and none of the high achievers tended to use completely new technologies to gain relative advantage when applying for jobs, although this choice necessitated them to cope with large knowledge gaps.
\end{abstract}

Index Terms-Information systems education, innovations in final project, technologies' selection.

\section{INTRODUCTION}

Most Information Systems (IS) programs include a final project in their curriculum [1] in which the students design and implement a complete information system in the last year of their studies. For that matter, the students have to find a customer, initiate, analyze and design a solution addressing one or more of the customer's needs, and develop an information system that follows the design. Students have the freedom to choose both the project's subject and the technology to be used for the implementation the project's software.

While some students choose to develop a unique and innovative system, others may prefer a more traditional system. Innovative projects require original thinking and creativity, and non-innovative projects require only replication of existing solutions.

The project provides the students with the opportunity to explore new technologies beyond what they have learned, and use them in their project in order to improve its functionality and visibility. While students may choose only technologies they are already familiar with from their studies, there are many reasons why they would want to invest the time and efforts required for learning and using new technologies in their projects. Among these reasons are, extending professional knowledge, demonstrate self-learning skills, gain mastery over some technology, etc. Investing time in incorporating new technologies in the project may raise their value among potential employers.

Some students may decide to extend their knowledge by gaining mastery over few or many software technologies. Other students may choose to explore technologies completely new to them (e.g., new programming language, new software package) and gain mastery over its basic principles as well as its advanced concepts. Obviously, minor extension of familiar technology is easier to accomplish than major one, and this in turn is easier to achieve than leaning a complete new technology. The time and efforts involved in each type of the above learning is accordingly. The greater the knowledge gap is, the greater the efforts required.

To be able to learn by themselves the students have to develop independent learner skills. Among the skills independent learners have to possess are: curiosity, persistency, self- motivation, critical thinking and reflection abilities regarding the learning progress [2]. In terms of self-regulated learning theory [3],[4], while applying self-learning, students are involved in a cyclic process in which they set learning goals, plan how to achieve them and evaluate their progress.

The research aims were to explore how students perceive the final project and its goals, and how these perceptions affect their decisions and actions regarding the level of innovativeness and complexity of the project and the extent to which they utilize advanced technologies beyond their existing knowledge. The research questions deriving from the above aims are:

(1) What were the expectations of the students from 
the final project?

(2) How these expectations affected the students' choice of the project's theme, the innovativeness of it, and its estimated complexity?

(3) What were the underlying reasons for the students' selections of technologies used to implement the software that addresses the project's specifications?

The rest of this paper is organized as follows. Next, we provide a brief description on the context of the study, then we present a theoretical background followed by the research method. The next section presents the results and discussion. Finally we present instructional implications and concluding remarks.

\section{THE CONTEXT OF THE STUDY}

According to the IS curriculum [1], IS programs include a capstone course in which students have to build a complete information system. The project is defined as a team effort that allows a final opportunity to practice personal and interdependence skills to ensure team members empowerment and success. The project has a structured framework that follows the life-cycle of a software product, aiming to facilitate the student's progress along the project timeline. The project is composed of three main phases: initiation, design and implementation. The students have to submit an initiation document followed by a system specification document, and then they have to implement a complete software system according to the handed specifications. The initiation document includes a precise description of the system, its users, its goals and feasibility tests. The design document includes a list of customers' requirements and a conceptual design of the planned system. The implementation phase includes the development of software in some development environments (e.g., tools, language, libraries, database, etc.). In addition to the developed system the students hand in user and maintenance guides. The maintenance guide includes a section in which the students elaborate on the technology, tools, and software libraries used to build the provided system.

The students are allowed to choose the customer for which the system is built for, the project theme, and the technology to be used for the implementation of the software. During their studies the students become acquainted with several technologies, most of them are at the basic level. The use of these known technologies enable the students to build a complete system, however, it is not usually sufficient for developing a complex and up-to-date system with modern components and technologies.

This project offers the students with an opportunity to expand their knowledge, improve their professional skills, and enrich their professional 'toolbox'. Students who choose to take the opportunity and cope with learning of new technologies have to overcome knowledge gaps. By knowledge gap we mean that the students have basic understanding of the issues under examination, but lack the advanced knowledge of these issues that is required to finish the development of the project. For example, students who decide to develop a mobile application have to master the mobile environment. Developing an application for mobile phones share many common features with computer-based systems, however it requires the use of different software libraries and different environment settings. As to another example, students who want to study and master a programming language that was covered during class (e.g., PHP) have to invest lots of efforts in learning new syntax, and gain basic understandings of the new environment. They have to invest many more efforts to master the advanced software libraries required for the development of their project. While the first example refers to a situation in which the knowledge gap is rather minor, the latter one refers to a much larger gap. Minor gap refers to cases in which the students have a fundamental knowledge of some technology and they are required to expand their knowledge to some extent. Major gap refers to cases in which the students have to learn from scratch new technology, or to widely expand knowledge of some known technology, way beyond current knowledge.

Students who decide to take the challenge of incorporating new technologies into their project take the responsibility of self-coping with the knowledge gaps involved. It is the students' responsibility to close the knowledge gaps and this is done and directed only by them. The students have to set learning goals, look for learning materials, and decide upon ways to practice. They perform ongoing monitoring of their progress and adjust their learning accordingly. Obviously, the learning goals are derived from the project's requirements, but the students are free to decide to which extent they are willing to expand their learning.

The project is conducted under the supervision of one of the academic staff of the Management Information Systems (MIS) department. The supervisor's role is to monitor the project progress, to provide feedback on the work processes, and to assess the outcomes. The students' work is assessed base on its correctness, completeness and accuracy. It is important to note that while the research was conducted the project's grade was not directly affected by the selection of technologies or the degree of innovation of the project, hence students may choose simple project, implement it via basic technology and get fine grade.

\section{RELATED WORKS}

In this section we bring a brief literature survey regarding the following issues: knowledge gaps and independent learner skills, and Self-regulated learning and independent learner skills.

\section{A. Knowledge Gaps and Independent Learner Skills}

In many of the courses learned in the undergraduate level, students are introduced with only fundamental knowledge of various aspects of technologies, due to time limitations. If students wish to deepen their 
knowledge and gain mastery over these technologies and understand the interconnections with other related topics, they have to learn further by themselves. Knowledge gap can be minor or extensive. To be able to overcome knowledge gaps in general, and in the area of information technologies in particular, the students have to develop independent learner skills [2]. Independent learner has to be curios, self-motivated, critical thinker, self-examiner and persistent. As to curiosity, independent learner has to be proactive and seeks for ways to widen his knowledge by himself. As to self-motivation, independent learner is motivated by setting goals to achieve and is driven mainly by his own personal achievements. As to critical thinking, to function effectively as an independent learner, one has to be able to filter important information from a given one and to be able to assimilate new knowledge with existing one and not just memorize new facts. As to self-examination, independent learner has to possess monitoring skills that enable him to navigate his learning process and to be aware to his strengths and weaknesses. As to persistence, Independent learner strives to understand new knowledge on his own before asking for help

\section{B. Self-Regulated Learning and Independent Learner Skills}

Self-regulated learning (SRL) is a process that supports students in organizing their thinking, behaviors, and emotions in order to successfully cope with their learning experiences [4]. SRL is especially important when referring to learning experiences of independent learners. Self-regulation is important to the learning process [5], [6]. It can help students improve their learning and develop their learning skills ([7]. It also can help students monitor their learning performance ([8], and evaluate their academic progress [9].

Models of SRL are composed from three main cyclic phases: Forethought and planning, performance monitoring, and reflections on performance [3], [4]. Within the forethought and planning phase, students examine and analyze the learning task and set goals toward its completion. To cope with knowledge gaps by self- learning the goal students set to themselves is to close these knowledge gaps. However they may not know the best ways to fulfil their goals. In these cases they can consult with experts such as lecturers or classmates. In the performance monitoring phase, students employ strategies to close the knowledge gaps and monitor the effectiveness of the used strategies for accomplishing the tasks they set to themselves. To avoid fixation by using strategies that do not facilitate the process of closing the knowledge gap, external monitoring and specific feedback from experts can help students consider the use of new strategies. In the third phase, students reflect on their performance and evaluate their achievements both practically and effectively with respect to the strategies they decided to use. These reflections influence students' future planning and goals, and initiating a new cycle to begin. Since after the execution of the above three phases, one never return to the exact starting point, hence we may say that the above SRL model is spiral rather than cyclic.

In the first phase of the cyclic model of SRL the students has to set learning goals and achieve them by monitoring their learning process. In our case, an external goal is set for the students, to plan and develop a final project. However, although the general goal is external, and stems from the need to provide a working system, some of the students set to themselves internal goal which is to develop a project using innovative environments which requires completion of knowledge. The completion of knowledge is project oriented. That is, the students learn the necessary information they need to successfully accomplish their project. During the learning of theses environments the students can reveal additional options that might improve their developed system further. Hence the learning process is dynamic and last as long as the students believe there is more in the technology to discover.

\section{THE STUDY}

In this section information regarding the following is presented: the research population and the environment in which the research took place, data collection and analysis tools.

\section{A. Environment and Population}

The study subjects are MIS graduates of the years 2013 and 2014 from a regional academic college. In these years 64 students have graduated. All the study participants have completed their academic duties including the final project.

\section{B. Data Collection and Analysis Tools}

The research included three phases. At the first phase we read and analyzed all the documents provided by the students as part of their project submission, including initiation document which describes the project's scope and goals, the design document which describes the system components and its complexity, and the maintenance document which provides information concerning the tools and technologies used by the students to implement the software. From these project's documents we classified each project according to its innovation level, its complexity, and the extent to which students challenged themselves to expand existing knowledge and learn new and unfamiliar environments to implement their project. The classification process was done separately by each of the researchers. They have reached similar results and after discussing the slight differences the classification was completed. Each one of the researchers classified and only after reaching an agreement regarding the classification

At the second phase, we disseminated a questionnaire including four open questions to the study participants. The questions refer to the students' expectations regarding the project, their decisions regarding the innovation of the project theme, the decision to use 
familiar or unfamiliar technologies, and the learning strategies used to overcome knowledge gaps.

By the first question we tried to grasp the students' expectations and their fulfilments towards the project, and the importance they attribute to the project. By the second question we tried to understand the reasons underlying the decisions that each team have taken concerning the project's theme. This decision refers to innovations, scope and complexity of the project. By the third question we tried to figure out reasons underlying the decision taken by the students concerning the use of familiar or unfamiliar technologies. By the last question we tried to understand the learning strategies used by the students to close knowledge gaps and the perceived advantages and shortcomings of these learning strategies by the students. The study participants' responses were analyzed using content analysis [10] and analytic induction [11]) to identify emerging categories.

At the third phase we chose ten graduates (five student couples) and conducted in-depth interviews with them, in order to gain better understanding of their decisions regarding the project's theme and the technologies used and for the establishing of the category set we arrived at the previous phase. These student couples provided us with additional insights on their decisions, and the underlying reasons. In order to grasp an overall view, we chose for these interviews students of different levels: high, average and low achievers. During the in-depth interviews, among the various questions that varied from couple to couple (depending on their previous answers), the students were asked questions referring to the following issues: their underling decisions to use familiar or unfamiliar technologies, and their perceived advantages and shortcomings of their learning strategies; and ways they coped with learning difficulties.

\section{RESULTS AND DISCUSSION}

In this section we first classify the projects into two types based on their innovativeness and complexity. Then we discuss the students' expectations from the projects and how these expectations affected the selection of the projects' themes. After that we discuss the underlying reasons provided by the students as regards to the technology they used for the implementation of the project. Finally we discuss the learning strategies the students used in order to cope with knowledge gaps and the perceived advantages and shortcomings of the applied learning strategies.

\section{A. Projects' Types}

By exploring the projects' documents, we noticed that the projects were developed using various technologies in variety of business domains. Observation of the projects and their characteristics revealed two main categories: basic projects and advanced ones. Stemming from our assumption that the main difference between basic and advanced project refers to the amount of efforts invested in each project type, we came with the following classifications. We classified a project to be a basic one if it included all of the following attributes: (1) the project theme is not original and other known software packages to it exist. The students' project focuses mainly on duplication of existing solutions; (2) the scope and complexity of the project is limited. This kind of project usually addresses merely the minimal requirements of the final project concerning the number of data files, dataentry forms and data-output reports. It usually does not include sophisticated data processing algorithms, complex data-structures or inter-relationships with external software systems; (3) the technology used for the implementation of the software is at the basic level. Most of the software if not all, is implemented via tools and environments learned during studies, perhaps with minor necessary extensions.

Advanced projects are characterized by at least one of the following attributes: (1) the project theme is original and it provides solution to a new problem or provides innovative solution to an existing problem. This kind of project involves business and/or technological innovations. The students do not replicate existing solutions but they elaborate them by exploiting new technologies and concepts; (2) the scope and complexity of the projects is wide. This kind of project usually involves much more data files, data-entry forms and dataoutput reports than the minimum required. It usually includes sophisticated data processing algorithms, complex data-structures or inter-relationships with external software systems; (3) the technologies used to implement the software are rather new. The software is implemented via software tools and/or environments that were not learned during studies, and requires major knowledge extensions beyond what was gained during class.

For illustration purposes we present three examples of projects that demonstrate the above classifications. The first project designed for use in a restaurant for registration of customer orders and production of management reports. The second project, RSVP (Repondez S'il Vous Plait), was developed as a mobile application for invitation submissions to social events, collection of the summoned responses including their meals' preferences, and a navigate function to the functions-hall via navigation software. The third project is a system developed for a building committee, in which tenants' payments, bills and maintenance operations are managed by the building representatives, and reports are provided to the building's inhabitants via an internet site.

The first project is an example of a basic project. Its specification and design are quite simple, and plenty of similar existing solutions are available. The implementation is also quite simple, as a stand-alone application installed and used on one computer. This project was built using merely technologies learned during studies, it includes minimal number of data files, data-entry forms and reports, and all data processes are basic. As a result, the provided system is superficial.

The second project is an example of an advanced project. Although RSVP software tools exist, the 
provided system included novel elements. Instead of relying on email messages (old technology), it provides an integrative solution with mobile application, internet website and SMS technology, that facilitates the summoned responses and provide new features such as invitation templates, meals' selection, and car navigation. Moreover, the system was deployed and used during the project duration on real wedding event with hundreds of guests who used the system and enjoyed it.

The third project is another example of advanced project. Although the project's theme is not innovative, it was developed using new technologies which necessitated an investment of many efforts in order to gain mastery over it. The resulted system included many data files, data-entry forms and reports. Obviously, there is a huge difference between the scope, complexity and quality of these three projects. Fig. 1 presents the project's type, and frequencies out of the 32 handed projects:

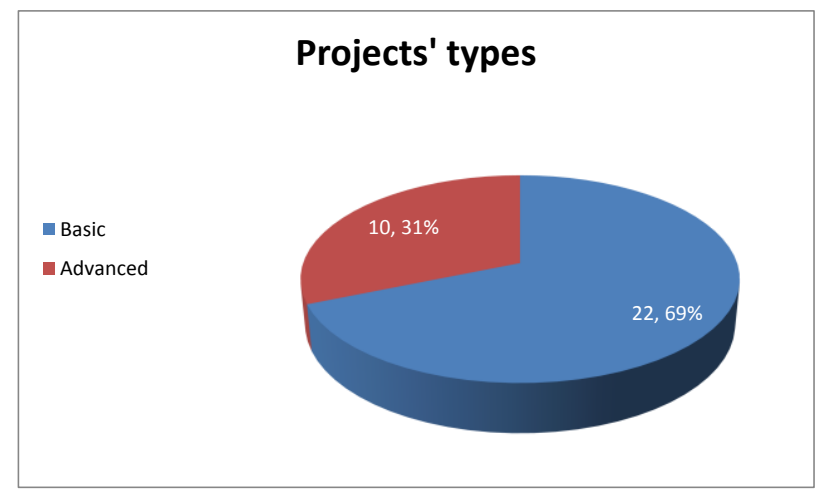

Fig.1. Project's Types and Frequencies

In Fig. 1 we present the projects' distribution according to the project types, based on the data gathered from the projects' documents regarding the project theme and its design. As shown, approximately two thirds of the study participants developed basic projects, and only one-third of them developed advanced ones.

\section{B. Classification of Students to Class Levels}

We suspected that there is a connection between the students' academic achievements and the type of project they developed. We assumed that mainly high achievers will take the challenge to cope with an advanced project. For that purpose we classified the students according to their total average score taken from the college administration system. Indeed we found a connection between the total average score and the project type that were selected by the students, but we also found interesting and surprising findings on which we will elaborate on later. We found that the average score of the study participants ranged between 58 and 99 . We classified the students into three categories according to their academic achievements, as shown in Table 1. As shown, the majority of the students are average achievers, and the high and low achievers share similar proportions.
Table 1. Students' Learning Levels

\begin{tabular}{|c|c|c|}
\hline Class level & $\begin{array}{c}\text { Average grade } \\
\text { range }\end{array}$ & No. of students \\
\hline $\begin{array}{c}\text { A (high } \\
\text { achievers) }\end{array}$ & $86-99$ & $11(17 \%)$ \\
\hline $\begin{array}{c}\text { B (average } \\
\text { achievers) }\end{array}$ & $72-85$ & $40(63 \%)$ \\
\hline C (low achievers) & $58-71$ & $13(20 \%)$ \\
\hline
\end{tabular}

\section{Use of Technologies}

We classified the projects according to the extent of use of advanced technologies beyond those learned during studies, as reported in the projects' documentation. For that purpose we scanned all the syllabuses of the courses that are part of the curriculum, and discussed them with the instructors and their teaching assistants. We made a list of all the programming languages, development environments, software packages, tools (e.g., databases, prototyping), protocols, and standards that were taught during studies, and compared them with the technologies reported by each project team. For the sake of simplicity we refer to all the above elements as 'technologies'. We classified the extent of use of advanced technologies to the following categories, as shown in Table 2.

Table 2. Extent of use of Advanced Technologies

\begin{tabular}{|c|l|}
\hline level & \multicolumn{1}{c|}{ Description } \\
\hline 1 & $\begin{array}{l}\text { Use of technologies that have been learned during the } \\
\text { various courses, without any extension }\end{array}$ \\
\hline 2 & $\begin{array}{l}\text { Use of technologies that have been learned during the } \\
\text { various courses, with minor extensions regarding some } \\
\text { advanced features (e.g., use of one or two extended } \\
\text { libraries) }\end{array}$ \\
\hline 3 & $\begin{array}{l}\text { Use of technologies that have been learned during the } \\
\text { various courses, with major extensions regarding many } \\
\text { advanced features (e.g., use of more than two extended } \\
\text { libraries) }\end{array}$ \\
\hline 4 & $\begin{array}{l}\text { Use of technologies that have not been learned during } \\
\text { the various courses as the infrastructure of the system } \\
\text { (e.g., new programming language) }\end{array}$ \\
\hline
\end{tabular}

\section{The Classification of Projects According to} Innovativeness and Complexity

We classified the projects based on their innovativeness and complexity level (See Section projects' types above) as revealed from the projects' documentation. Fig. 2 presents the projects' distribution according to the extent of use of advanced technologies in the project. We can learn that majority of the students (approximately 70\%) decided to implement their projects using environments and technologies they were already familiar with from their studies. In Fig. 3 we present the percentage of students from each class level according to technology used. 


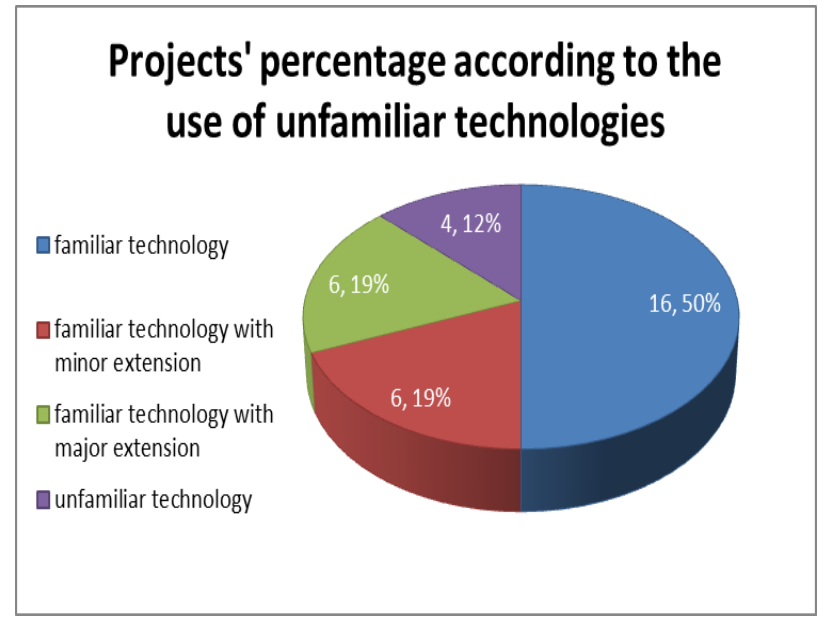

Fig.2. Projects' Percentage According to the use of Unfamiliar Technologies

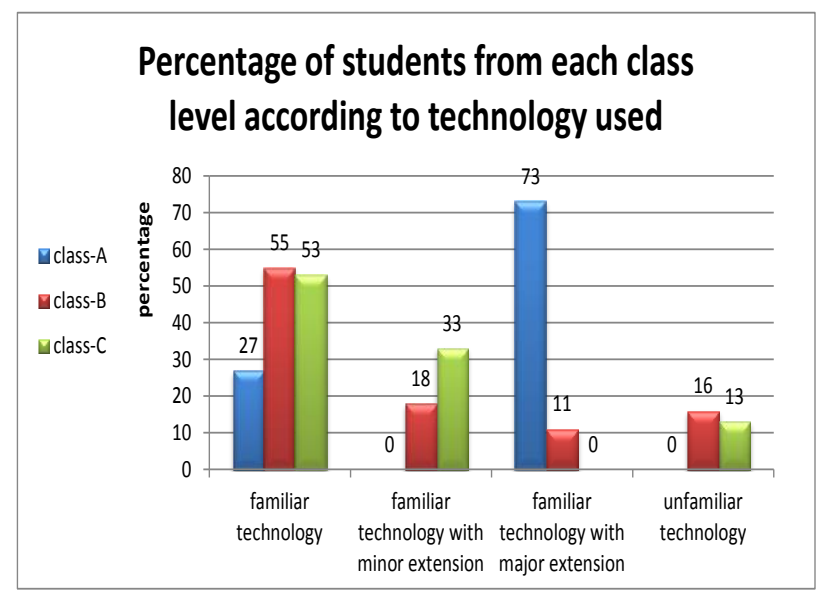

Fig.3. Percentage of Students from Each Class Level According to Technology Used

Seven out of $32(22 \%)$ projects were innovative according to the definition of innovation stated above. Almost all of these projects were performed by teams in which at least one of the students was a class-A student and no one of them was from class-C. Research has found that self-efficacy and the use of self-regulation strategies to have reflexive positive influence on one another. Higher self-efficacy beliefs results in an increase of the use of self-regulation strategies [12] and the use of self-regulation strategies may cause an increase in selfefficacy beliefs and academic achievements [13]. [14] found that students with high levels of positive selfefficacy accomplish academic tasks more successfully and tend to cope with difficult tasks and be motivated to use various strategies to solve problems than students who do not believe in their own abilities.

From Fig. 2 we can learn that 16 out of $32(50 \%)$ projects used familiar technologies to implement the project. As demonstrated in Fig. 3, above 50\% of average and low achievers, and $27 \%$ of high achievers used familiar technologies to implement the project. As to use of minor extension of familiar technologies, $33 \%$ of low achievers, $18 \%$ of average achievers and $0 \%$ of high achievers were classified to this category. As expected, none of the low achievers and only $11 \%$ of average achievers chose to majorly extend the use of familiar technologies, and approximately three quarters of high achievers fell under this category. Surprisingly, none of the high achievers took the opportunity to learn and master new technology to implement the project.

The most unexpected finding observed in Fig. 3 is that $16 \%$ of average achievers and $13 \%$ of low achievers chose to implement their project using completely new technologies. We elaborate later on their underlying reasons.

It worth noting that most of the projects, in which students used completely unfamiliar technologies, were not categorized as innovative. To be able to develop an innovative project the students have to demonstrate creative thinking and originality. These attributes are usually found in high achievers as was found by [14].

In what follows we further analyze the responses of the students to the questionnaire provided in the second phase of our research. We also provide representative selected quotes taken from the third phase of the research (interviews) to establish our analysis. For the in-depth interviews we selected six teams representing all levels of achievers, who provided us with additional insights on their decisions regarding the choosing of the project's theme and the technology they used for its development.

\section{E. Goals Perceived by the Students Regarding the Final Project}

Analysis of the students' responses to the questions regarding their expectations from the final projects and implications on the project theme selection revealed the following emerging categories: 'meet the challenge', 'get a good score', 'become an expert', 'extend my knowledge', 'gain experience', 'make an impression'.

Fig. 4 demonstrates the percentage of students from each class level (A, B and C) referring to above categories. For example, in the category 'meet the challenge', 11 out of 13 (85\%) class-C students, 6 out of $40(15 \%)$ class $-\mathrm{B}$ students and 3 out of $11(27 \%)$ class A students referred to this category.

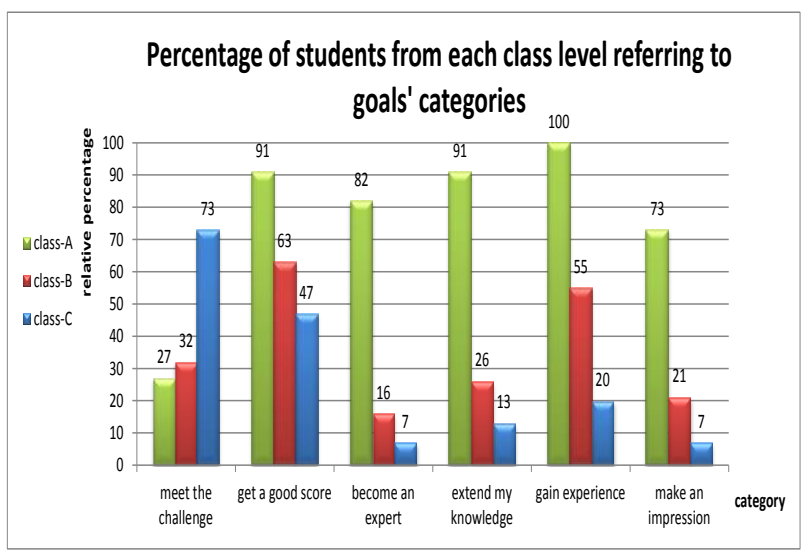

Fig.4. Percentage of Students from Each Class Level Referring to Goals' Categories.

As can be seen from Fig. 4, except from the first goal: 'meet the challenge' in all other categories the percentage of high achievers is the dominant. In terms of SRL [5], [6] 
high achievers tend to set themselves ambitious goals regarding academic tasks they are engaged with. Herein, we elaborate on each category.

Meet the challenge. 26 students ( 3 class-A, 12 class-B, 11 class-C) expressed their concerns regarding their abilities to cope with the project's requirements and finish its development on time. As shown, class-C students were mostly concerned with the requirements. The following excerpts (taken from the interviews) demonstrate the students' concern:

Ehud (class-C): "I was a little concerned about the project. Unlike other courses, in this course we were all by ourselves, and I was not sure that we (me and my partner) could carry out project of this magnitude on our own and finish it on time".

Tami (class-A): "The third year is very busy. We have many complex assignments, and I started to work in the field at the end of last year. Therefore I was afraid that I would not find the time to invest in the project ".

From Ehud's excerpt we can learn that Low-achievers expressed concerns regarding their abilities to meet the challenges of developing a complete information system without teacher support. According to [15] low achievers need more support from teachers than high achievers in order to accomplish their learning tasks. Since constructing information system is considered to be a complex and comprehensive task, supporting low achievers is crucial. On the other hand, Tami's reflection demonstrate that High-achievers are not afraid to take on additional tasks if they believe it will help them, and know how to adjust the various needs of these tasks.

Get a good score. 41 students (10 class-A, 24 class-B, 7 class-C) expressed wishes to receive a good score. They recognized the final project to be an important and significant task. Herein representative quotes:

Tami (class-A):"I wanted to get an excellent score, one that reflects my professional abilities as a MIS graduate."

Joseph (class-B):" It was important to me to get a good score in the project since it has a relatively high credit and it affects the total average score."

Debby (class-C):"My average score does not reflect my real abilities. Hence, I had a strong motivation to prove otherwise and get a good score in the project."

As can be seen from Fig. 4, the higher the class level the student belong to the higher the motivation to get a good score. While $91 \%$ of the high achievers, set goal to themselves to maintain their academic level by getting a good score, as was reflected by Tami, only half of average and low achievers set themselves this goal. It is in line with [14] who found that high-achievers have high expectations from themselves regarding academic achievements while low achievers tend to be satisfied with average scores. Additional reasons for the expectation to get a good score are specified by Joseph and Debby: improve the total average score and demonstrate professional abilities despite poor academic achievements.

Become an expert. 16 students ( 9 class-A, 6 class-B and 1 class-C) set themselves a goal to become an expert in the technology they used to develop their project. Herein representative excerpts:

David (class-A):"during studies we were exposed to many features of the java programming language, but there were many features left outside. Becoming an expert in Java requires the learning of these features. I decided to exploit the project for this purpose and gain mastery in it. I did it because I believe it will raise my chances to get a decent job upon graduation."

Ben (class-B):"When you come to job interview they expect you to demonstrate expertise in one or more IS domains. Hence it was important to me to develop professional expertise via the development of the project."

Being aware to the industry demands, students on the verge of their academic studies know they have to demonstrate high technical and cognitive abilities during job interviews in order to get desirable jobs. In terms of SRL [3], [4], we may say that within the first phase of SRL, forethought and planning, students examine and analyze the project's requirements and set ambitious goals such as to exploit this task for developing expertise in the development environment. It seems that these goals stem from external motivation which relate to the IS industry demands.

Extend my knowledge. 22 students (10 class-A, 10 class-B and 2 class-C) referred to the extension of their professional knowledge as a goal.

Alex (class-A): "We have studied to develop Web applications; however we didn't delve into the various technologies thoroughly. The project provided me with an opportunity to complete the missing knowledge."

Daphna (class-B): "I forgot many of the subjects that have been learned during the first two years. I don't want to attend job interviews in this situation. During the project I could rehearse these subjects and even further extend my knowledge with new subjects. "

Though this goal resembles the previous one, we classified them into separate categories. We believe that extending current knowledge express modest expectations to gain additional knowledge to a certain extent, while becoming an expert express more ambitious goal referring to gaining mastery over the whole technology. Fig. 4 shows that the percentage of highachievers who specified the goals 'become an expert' and 'extend my knowledge' is much higher than the percentage of the other students in these categories. However, it can be seen that the percentage of average and low achievers who set themselves the goal of knowledge extension is higher than the percentage of average and low achievers who set the goal of becoming experts. According to [14] high achievers tend to set more ambitious goals and are motivated to accomplish 
them than average or low achievers, as can be observed from the differences between Alex and Daphna's goals. The above findings support [14] observation.

Gain experience. 35 students (11 class-A, 21 class-B and 3 class-C) included this goal in their reflections. Herein representative quotes from the students' reflections:

David (class-A):"I heard from colleagues that employers prefer experienced programmers. The project will provide the required experience. "

Joseph (class-B):"Since I did not have the opportunity to build a complete information system so far, this is my first experience in such a complex and comprehensive task."

Michael (class-C):"Gaining a certain experience in developing a complete information system, will provide me with an indication whether or not this profession suits me."

The students refer to a disturbing situation in which unexperienced graduates tackle difficulties in applying for their first professional job especially in case they lack up to date professional knowledge [16]. Being aware to this problem, students refer to the project as means for gaining a certain professional experience that will facilitate their entry to vocational career. While for high and average achievers, like David and Joseph, gaining this experience conceived as challenging yet achievable, for low achievers, like Michael, it is a kind of test for their professional capabilities with implications to their professional career.

Make an impression. 17 students ( 8 class-A, 8 class-B, 1 class-C) reported on building an impressive system as a goal. As examples of such report, we present reflections of Tami and Alex.

Tami (class-A): "I want my project to be impressive. It is important to me that it will be innovative and unusual so that potential employers will appreciate my efforts".

Judith (class-B): "The project is my professional business card. It summarizes all the knowledge I have acquired during my studies and the professional skills that I developed. I know I shall present the final project in job interviews, and it can influence my chances to get the job".

From Tami's and Judith's excerpts we can learn that high and average achievers perceived the project as means for expressing their professional capabilities. Both of them understand the importance of the project as mean to attract the attention of future employers. According to [17], employers attribute high importance to students' grade on their entry level job.

Observing the above goals reveal that they can be divided into mastery and performance goals ([18]. The goals 'meet the challenge' and 'get a good score' can be classified as performance goals in which external motivations are involved. The goals 'becomes an expert'; 'extend my knowledge'; 'gain experience', and 'make an impression' can be classified as mastery goals. Students with mastery goals are motivated by improving their abilities, developing new skills and gaining mastery according to personal standards. They are keen to extend their professional knowledge and become experts, and evaluate their success by examining their abilities to use this acquired knowledge properly [19], [20], [21]. Students with performance goals are mainly interested in whether they can perform given assignments properly. They seek for success avoid or give up quickly when tackled difficulties. As can be seen from Fig. 4, mastery goals are set by high achievers in higher percentage while performance goals are more common among average and low achievers.

In terms of SRL [5], [6], although there was an external motivation that refer to the role of the project as a professional business card, the students expectations from the project stem from their self-perceptions regarding their learning capabilities. While highachievers set themselves challenging goals that their fulfilment will demonstrate their professional potential, low-achievers, set modest goals they will be able to accomplish. We may assume that students that decided to develop systems including innovative elements and ideas, were motivated by internal (am I capable to accomplish the task?) and by external (I can gain relative advantage while looking for job) reasons.

\section{F. Reasons Underlying the Selection of Technological Environments}

In this section we provide an analysis of the students' responses to the questions referring to the underlying reasons for the selection of technologies used to implement the project. We divided the provided reasons into two categories, the ones referring to the use of familiar technologies or minor extension of them, and to the ones referring to the use of major extension of familiar technologies or the use of unfamiliar ones. We made this classification since the provided reasons in each of the above categories were similar. First we discuss reasons provided by students who selected familiar technologies or minor extension of them. Then, we discuss reasons provided by students who used familiar technologies with major extensions or unfamiliar technologies.

\section{(a) Reasons for Using Familiar Technologies or Minor Extensions of them}

Students provided four main reasons for their selection of familiar technologies or minor extension of them. In Table 3 we present distribution of students who provided the given reasons according to their class level.

As shown in Table 3, the students provided four reasons uttered in similar words. Table 3 also presents the number of students among the ones who selected familiar technologies or minor extension of them according to their class level. In what follows we elaborate on each of the provided reasons and discuss these reasons with relation to the research literature at the end of this section. 
Table 3. Distribution of Students According to Provided Reasons and Class Level

\begin{tabular}{|c|c|c|}
\hline Reason & Class level & No. of students \\
\hline \multirow{2}{*}{$\begin{array}{c}\text { Perceived } \\
\text { complexity of the } \\
\text { project }\end{array}$} & $\mathrm{A}$ & 0 out of 3 \\
\cline { 2 - 3 } & $\mathrm{B}$ & 12 out of 28 \\
\hline \multirow{2}{*}{$\begin{array}{c}\text { Doubt in ability to } \\
\text { cope with new } \\
\text { technology }\end{array}$} & $\mathrm{C}$ & 8 out of 13 \\
\cline { 2 - 3 } & $\mathrm{A}$ & 0 out of 3 \\
\hline \multirow{2}{*}{$\begin{array}{c}\text { Heavy demands in } \\
\text { other courses }\end{array}$} & $\mathrm{B}$ & 7 out of 28 \\
\cline { 2 - 3 } & $\mathrm{C}$ & 10 out of 13 \\
\hline \multirow{2}{*}{$\begin{array}{c}\text { Familiar } \\
\text { technology is good } \\
\text { enough }\end{array}$} & $\mathrm{A}$ & 15 out of 28 \\
\cline { 2 - 3 } & $\mathrm{B}$ & 12 out of 13 \\
\cline { 2 - 3 } & $\mathrm{C}$ & 13 out of 3 \\
\hline
\end{tabular}

Perceived complexity of the project. The students expressed their concerns regarding the complexity of the project and the time they will have to invest to accomplish it. They felt that learning new technologies will divert their attention from engagement with the project. The following quotes represent these concerns:

Debby (class-C): "We were worried by the demands and the extent of the project and felt that if we invest efforts in learning new technologies; we will not be left with sufficient time to address the project's demands. Hence, we decided to use programming environment we already know in order to be able to cope with the complexity of the project demands."

Joseph (class-B): "It took me a long time to recall previous learnt materials required for this project. I didn't have time to invest in learning additional materials."

Table 3 shows that this reason was provided by approximately half of average and low achievers (among those who selected familiar / minor extension), and none of the high achievers.

Doubt in ability to cope with new technology. Average and low achievers admitted that they do not consider themselves as good programmers and hence expressed doubts regarding their capabilities to cope with learning new technologies. Herein representative excerpts:

Michael (class-C) "I am not very good in programming. Actually I was afraid from the programming task involved in the project. I realized that developing a project will be very difficult for me and my partner, even if we use familiar environments."

Judith (class-B): "Programming was always a challenge for me. Learning by myself new technology is way beyond my abilities."

Table 3 shows that this reason was provided by more than half of low achievers and quarter of average achievers (among those who selected familiar / minor extension), and none of the high achievers.

Heavy demands in other courses. The students reported on experiencing heavy demand during the last study year and lack of time to invest further in learning new technologies. They felt they have to balance between the efforts invested in the project and the efforts invested in other courses. Herein representative quotes:

Ehud (class-C), "The last year of studies is very intensive. Despite the fact that I invest a lot of efforts in each course, I hardly get good scores. I was afraid to fail in the courses of this year and therefore invested every free minute to avoid failures.

Alex (class-A): "During this year I participated in a practicum project and took three elective courses which necessitated a lot of efforts. It was important to me to succeed in these courses as well as in the project. "

Table 3 shows that this reason was provided by the majority of students in all class levels (among those who selected familiar / minor extension).

Familiar technology is good enough. Approximately half of the average and low achievers expressed satisfaction from using familiar technology with or without minor extension of it. They believe that the technologies they used was good enough for the purpose of the project implementation. Herein representative quotes:

Debby (class-C): "I believe that the environment I chose was good enough, otherwise the lecturers would not use it for instruction. I could find other technologies to implement the software, but I see no reason for doing so."

Ben (class-B): "I think I gain better control over the familiar environment, and even expand my knowledge to some extent. I am very pleased with the result".

The reasons provided by the students who decided to use familiar tools and technologies reflected the students' self-perceptions regarding their programming capabilities. It is well known that there is a connection between low achievers and their self-esteem concerning their learning abilities [22]. As demonstrated by Debby's and Joseph's excerpts, viewing the project's requirements raised the students' concerns whether they are capable to cope with. Having negative previous experience with programming did not contribute to their self-perception regarding their capabilities to cope with the project's demands, as can be concluded from Michael's and Judith's excerpts. Engagement with familiar environments is challenging, and requires intensive efforts to accomplish the task for average and low achievers. As a result, they demonstrate less enthusiasm in coping with projects that their development necessitates the learning of extra knowledge. This is in line with [23] who found that low achievers tend to demonstrate low interest and management capabilities while engaging in learning tasks. Ehud's and Alex's excerpts indicate that for some students, the selection of familiar technologies was a result of realization that coping with both intensive demands of other courses and the project requirements is beyond their abilities. Hence they tried to minimize the amount of new 
knowledge they have to cope with. This is in line with [24] who found that average students tend to adjust the level of tasks they are engaged with to their perceived capabilities. Some other students, like Debby and Ben, justified their choice by saying that they believe this was the proper technology to use for the development of their project. Nevertheless, they feel satisfied and rewarded by self-learning of advanced features of this environment. This is in line with [25] who found that one of the outcomes of self-regulation learning is satisfaction of the basic psychological needs for autonomy and competence.

(b) Reasons for Using Major Extension of Familiar Technologies or Unfamiliar ones

Students provided three main reasons for their selection of using familiar technologies with major extension of them or the use of unfamiliar ones. In Table 4 we present distribution of students who provided the given reasons according to their class level.

Table 4. Distribution of Students According to Provided Reasons and Class Level

\begin{tabular}{|c|c|c|}
\hline Reason & Class level & No. of students \\
\hline \multirow{2}{*}{$\begin{array}{c}\text { Challenge their } \\
\text { learning } \\
\text { capabilities }\end{array}$} & $\mathrm{A}$ & 6 out of 8 \\
\cline { 2 - 3 } & $\mathrm{B}$ & 3 out of 10 \\
\hline \multirow{2}{*}{$\begin{array}{c}\text { Gain mastery and } \\
\text { extend knowledge }\end{array}$} & $\mathrm{C}$ & 0 out of 2 \\
\cline { 2 - 3 } & $\mathrm{A}$ & 8 out of 8 \\
\hline \multirow{2}{*}{$\begin{array}{c}\text { Vast use in the } \\
\text { industry }\end{array}$} & $\mathrm{B}$ & 8 out of 10 \\
\cline { 2 - 3 } & $\mathrm{C}$ & 1 out of 2 \\
\cline { 2 - 3 } & $\mathrm{A}$ & 3 out of 8 \\
\hline
\end{tabular}

As shown in Table 4, the students provided three reasons uttered in similar words. Table 4 also presents the number of students providing each reason according to their class level. In what follows we elaborate on each of the provided reason and discuss these reasons with relation to the research literature at the end of this section.

Challenge their learning capabilities. The students expressed their motivations regarding the use of major extension of familiar technologies or using unfamiliar ones saying they wanted to challenge their learning abilities and prove themselves that they can cope with such tasks. The following quotes represent these motivations:

David (class-A): "We chose to develop software that required the learning of new software packages. In a way we challenged ourselves to delve into the domain of $3 D$ graphics which we were not exposed to during our studies. Developing such a system necessitates high-level graphics and sophisticated algorithms. We did it because we wanted to challenge ourselves with a non-standard project. It is true that we wanted our project to be different than the others, but it was also important for us to prove ourselves that we are capable to accomplish the project. We are very proud of the outcomes".

Daphna (class-B): "In this field technology changes very often. I deliberately decided to choose unfamiliar environment in order to prove myself that I can learn new technology by myself. I am sure that future employers will be impressed from that choice and the efforts will be worthwhile."

Ben (class-B):"Since my academic achievements are only average, I knew I had to provide potential employers another proof for my abilities. In the selection of new and unfamiliar programming language I convey a message that although my grades are average, I am actually excellent."

Table 4 shows that this reason was provided by two thirds of high achievers and one third of average achievers (among those who selected major extension of familiar or unfamiliar technologies).

Gain mastery and extend knowledge. Additional reason provided by the students referred to their wish to gain mastery of the technology used and extend their current professional knowledge. The following quotes represent these wishes:

Tami (class-A): "For the implementation phase of the project we chose Dot.Net environment we learned during studies, and had to extend our knowledge to be able to implement advanced features and gain mastery of Dot.Net environment."

Joseph (class-B): "Mobile applications are very hot nowadays, and the industry is looking for people who can develop applications for them. We chose to develop a mobile system and during the development we became enthusiastic about it, and hence I learned almost everything related to it. Upon graduation, I plan to start a new company with my partner, to address small business's needs."

Table 4 shows that this reason was provided by majority of the students (among those who selected major extension of familiar or unfamiliar technologies) regardless their class level.

Vast use in the industry. The final reason provided by the students referred to their awareness of the specific programming environments required by the industry. The following representative quotes refer to this issue:

Joseph (class-B): "We were looking at job posting, and tried to figure out what professional knowledge is required. We found out that there is a very popular environment that we did not study during our academic studies. Hence, we decided to develop our project using that environment, and raise our chances to get a decent job after graduation".

Ben (class-B): "I heard from friend that are already working in the industry that it is worthwhile to learn and gain mastery in a certain technology, since it becomes very popular and there demand for experts in this field."

Table 4 shows that this reason was provided by more than half of high achievers and one third of average achievers (among those who selected major extension of familiar or unfamiliar technologies).

From David's excerpt we can conclude that high achievers are curious about their abilities and challenge 
themselves by self-extension of their professional knowledge. This is in line with [2] who found that one of the skills independent learner has to possess and develop is professional curiosity. Joseph's excerpt demonstrates that some students tune their technology selections according to the sub-domain in which they want to specialize in. They use the project as a means to develop the required expertise and be ready to start their professional careers upon graduation.

From Tami's and David's excerpts we can learn that high achievers see the project as a means to demonstrate their excellence. They invest time and efforts to design innovative system, and invest more time and efforts to implement it in the most professional manner. We may assume that high achievers do not choose completely new technologies but majorly extend familiar one since they do not need to prove their academic excellence. Therefore they focus their efforts in extending their knowledge of familiar environments to build professional software, instead of investing efforts in learning from scratch new environments.

The most striking finding is that all the students who chose to develop their projects with new and unfamiliar technologies were average and low achievers. They provided two explanations for their interesting selection. The first refers to external motivation of enrichment of their professional business card. The second refers to their understanding of the importance of developing selflearning abilities in the IS domain and its value in the eyes of the potential employer.

From the excerpts of Joseph, Daphna and Ben we can learn that there were few reasons underlying the students' decisions for selecting new technological environments for their projects. One reason can be attributed to external motivation that made them invest efforts in gaining mastery of new tools and technologies. This motivation stems from the understanding that the project they develop can serve as a relative advantage and leverage to vocational lives. They are aware to the fact that presenting a project that its development necessitated a great deal of self-learning will be more appreciated by future employers who prefer workers with independent learner skills ([26], [27]. Driven by this motivation the students chose the type of project they want to develop one which its development necessitated the use of advanced tools and technologies. Additional reason provided by Ben referred to the will to compensate on average academic achievements by proving self-learning capabilities. Joseph's motivation to learn and use technology that he was not familiar with stems from his will to start his professional career as a mobile application developer.

\section{INSTRUCTIONAL IMPLICATIONS}

Analysis of the research data revealed that only one third of the participants chose to challenge themselves in either major extension of familiar technologies or in coping with new ones. Since we believe that self-learning capabilities are essential for vocational career in general and in the IS domain in particular, we recommend on taking measures to increase the percentage of students that incorporate new technologies into their projects. To achieve this goal we suggest that the projects' advisors should encourage the students to select innovative projects' themes and incorporate advanced technologies in their developed systems. This encouragement should also be reinforced by assigning significant weight to originality and complexity of the suggested project when assessing it.

Low and average achievers need more support in the process of closing knowledge gaps than high achievers. Hence, we recommend on providing these students with a scaffolding support. Namely, the advisor should take an active role in the closure of knowledge gaps, by building a structured program in which students are given from time to time a small task referring to some knowledge gap and be provided with feedback [28]. Gradually the control on the learning process will be shifted to the students' responsibility, so that eventually they will be able to monitor their learning process independently and become successful self-regulated learners [3, [4].

\section{CONCLUDING REMARKS}

We found that approximately two thirds of the study participants chose to develop basic projects, and only one-third of them chose to develop advanced ones. For the one third of the study participants the project served as a catalyst for gaining mastery over new and advanced technologies. The students who choose to invest efforts in learning new technologies were aware to the fact that this learning might provide them with an advantage when seeking job upon graduation.

Even students who did not take the challenge and chose to develop their project with familiar environments, also needed to cope with some knowledge gaps since they had to rehearse previous knowledge and sometimes even use advanced software libraries of these environments which were unfamiliar to them. To be able to close these gaps they had to demonstrate independent learner capabilities.

The research data revealed that there was a connection between the students' learning achievements and their willingness to accept challenges concerning the learning of new technologies. While high achievers tended to develop their projects using familiar technologies with major extension of them, part of the average and low achievers tended to use unfamiliar technologies. On the other hand most of average and low achievers tended to use only familiar technologies with or without minor extension of them to avoid the need of coping with meaningful knowledge gaps.

It can be said that within the general framework of the project the students applied SRL [5], [6] by setting learning goals, looking for strategies to achieve them, and handling learning difficulties they encounter during learning. The goals they set to themselves were an outcome of their self-perception of their abilities to cope with the extent and the complexity of the project. It can 
be seen that average and high achievers tend to utilize their inner resources to cope with learning difficulties by either rehearsing over the unclear parts of the tutorials they were engaged with or by discussing the learning materials in order to clarify blur issues.

\section{REFERENCES}

[1] Gorgone, J., Davis, G. B., Valacich, J. S., Topi, H., Feinstein, D. L., \& Longenecker, H. E. "IS 2002 Model Curriculum and Guidelines for Undergraduate Degree Programs in Information Systems". The Communications of the Association for Information Systems, 11, article 1. 2003.

[2] Meichenbaum, D., \& Biemiller, A. "Nurturing Independent Learners: Helping Students Take Charge of Their Learning". Brookline Books, PO Box 1047, Cambridge, MA 02238; tele. 1998.

[3] Pintrich, P. R., \& Zusho, A. "The development of academic self-regulation: The role of cognitive and motivational factors". In A. Wigfield \& J. Eccles (Eds.), Development of achievement motivation (pp.249-284). San Diego, CA: Academic Press. 2002.

[4] Zimmerman, B. J. "Attaining self-regulation: a social cognitive perspective". In M. Boekaerts, P. R. Pintrich, \& M. Zeidner (Eds.), Handbook of self-regulation. San Diego: CA: Academic Press. 2000.

[5] Zimmerman, B. "Investigating self-regulation and motivation: Historical background, methodological developments, and future prospects". American Educational Research Journal, 45(1), 166-183. 2008.

[6] Jarvela, S., \& Jarvenoja, H. "Socially constructed selfregulated learning and motivation regulation in collaborative learning groups". Teachers College Record, 113(2), 350-374. 2011.

[7] Wolters, C.A. "Regulation of motivation: Contextual and social aspects". Teachers College Record, 113(2), 265283, 2011.

[8] Harris, K. R., Friedlander, B.D., Saddler, B., Frizzelle, R. \& Graham, S. "Self-monitoring of attention versus selfmonitoring of academic performance: Effects among students with ADHD in the general education classroom". Journal of Special Education, 39 (3), 145-156, 2005.

[9] De Bruin, A.B., Thiede, K.W., \& Camp, G. "Generating keywords improves metacomprehension and selfregulation in elementary and middle school children". Journal of Experimental Child Psychology, 109 (3), 294310, 2001.

[10] Neuendorf, K. A. "The Content Analysis Guidebook". Thousand Oaks, CA: Sage Publications. 2002.

[11] Taylor, S.J. \& Bogdan, R. "Introduction to Qualitative Research Methods". New York: John Wiley \& Sons. 1998.

[12] Usher, E. L., \& Pajares, F. "Sources of self-efficacy in school: Critical review of the literature and future directions". Review of Educational Research, 78, 751796, 2008.

[13] Bouffard-Bouchard,T. Parent, S. \& Larivee, S. "Influence of self-efficacy on self-regulation and performance among junior and senior high school aged students". International Journal of Behavioral Development, 14, 153-164, 1991.

[14] Pajares, F., \& Graham, L. "Self-efficacy, motivation constructs, and mathematics performance of entering middle school students". Contemporary Educational Psychology, 24(2), 124-139, 1999.

[15] Slavin, R. E. "Achievement effects of ability grouping in secondary schools: A best-evidence synthesis". Review of educational research, 60(3), 471-499, 1990.

[16] Gallagher, K. P., Kaiser, K. M., Simon, J. C., Beath, C. M., \& Goles, T. "The requisite variety of skills for IT professionals". Communications of the ACM, 53(6), 144$148,2010$.

[17] Rosenbaum, J. E. "Beyond College for all: Career paths for the forgotten half". Russell Sage Foundation. 2001.

[18] Linnenbrink, E. A., \& Pintrich, P. R. "Multiple pathways to learning and achievement: The role of goal orientation in fostering adaptive motivation, affect, and cognition". 2000.

[19] Ames, C. "Classrooms: Goals structures and student motivation". Journal of Educational Psychology, 84(3), 261-271, 1992

[20] Maehr, M. L. \& Midgley, C. "Transforming School Cultures". Boulder CO: Westview Press. 1996.

[21] Nicholls, J.G. "The Competitive Ethos and Democratic Education". Cambridge, Massachusetss: Harvard University Press. 1989.

[22] Banks, M. \& Woolfson, L. "Why do students think they fail? The relationship between attributions and academic self-perceptions". British Journal of Special Education. 35 (1), 49-56, 2008.

[23] Lodewyk, K.R., Winne, P.H. \& Jamieson-Noel, D.L. "Implications of task structure on self - regulated learning and achievement". An International Journal of Experimental Educational Psychology.29 (1), 1-25, 2009.

[24] Bandura, A. "Self-efficacy". In V. S. Ramachaudran (Ed.), Encyclopedia of human behavior (Vol. 4, pp. 7181). New York: Academic Press. 1994.

[25] Deci, E.L., Ryan, R.M. \& Williams, G. C. "Need satisfaction and the self-regulation of learning". Learning and Individual Differences. 8, (3), 165-183, 1996.

[26] Lavy, I. \& Yadin, A. "Soft skills - An important key for employability in the "shift to a service driven economy" era". International Journal of e-Education, e-Business, $e$ Management and e-Learning, 3, (5), 416-421, 2013.

[27] Gillard, S. "Soft Skills and Technical Expertise of Effective Project Managers". Issues in Informing Science and Information Technology, 6, 725. (2009) Retrieved from http://iisit.org/Vol6/IISITv6p723-729Gillard599.pdf.

[28] Butler, D. L., \& Winne, P. H. "Feedback and selfregulated learning: A theoretical synthesis". Review of Educational Research, 65, 245-281, 1995.

\section{Authors' Profiles}

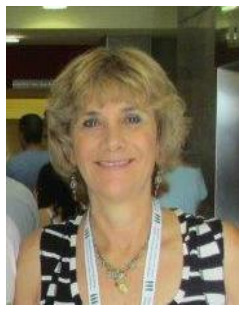

Prof. Ilana Lavy: is an associate professor with tenure at the Academic College of Yezreel Valley. Her $\mathrm{PhD}$ dissertation (in the Technion) focused on the understanding of basic concepts in elementary number theory. After finishing doctorate, she was a post-doctoral research fellow at the Education faculty of Haifa University. Her research interests are in the field of pre service and mathematics teachers' professional development as well as the acquisition and understanding of mathematical and computer science concepts. She has published over hundred papers and research reports (part of them is in Hebrew). 


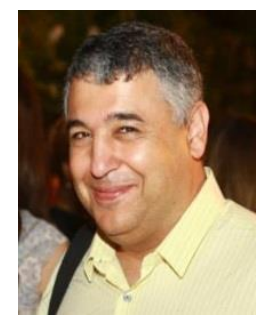

Dr. Rami Rashkovits: is a senior lecturer at the Academic College of Yezreel Valley since 2000 in the department of Management Information Systems. His $\mathrm{PhD}$ dissertation (in the Technion) focused on content management in wide-area networks using profiles concerning users' expectations for the time they are willing to wait, and the level of obsolescence they are willing to tolerate. His research interests are in the fields of distributed systems as well as computer sciences education.

How to cite this paper: Lavy I., Rashkovits R.,"Motivations of Information System Students in Final Project and their Implications to Technology and Innovation", International Journal of Modern Education and Computer Science(IJMECS), Vol.8, No.2, pp.1-13, 2016.DOI: 10.5815/ijmecs.2016.02.01 